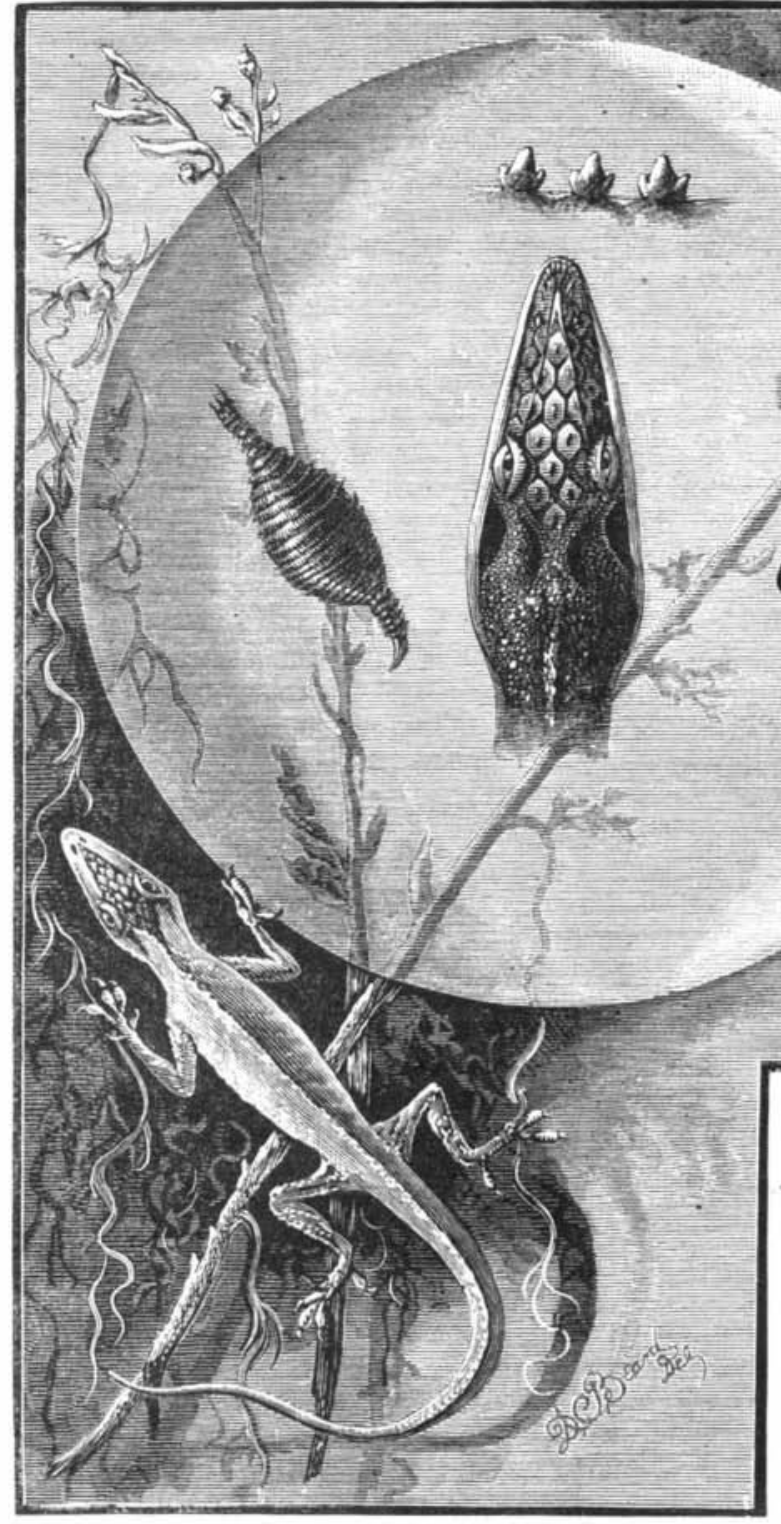

GREEN CAROLINA ANOLIS; OR, THE ANCRICAI

\section{CBAMELEON.}

Perbaps the first creature that attracts the eye of the Northern naturalist upon landing at Florida is a small, slender lizard, which appears omnipresent, to be seen running up and down the walls of the Old Fort at St. Augustine, peering in at the windows of the hotel at Pilatka, scampering over the logs of the swamp at Tocoi, or scrambling along the garden fences at Jacksonville. It may also be seen exhibited for sale along with young alligators, wildcats, black bears, and many other queer objects to be found

in the jewelry stores at Jacksonville.

The specimen from which my illustrations are made

ptured at Tocoi. When first ingents appear to be contained in a network hand. black; five minutes afterward, taken he was of a sooty of vessels beneath the skin, and to be somewhat, though not The boat has a removable upper portion, which is secured chief in which I was carrying him to show thy handker- altogether, under control of the animal. One, placed upon to the bull by means of bolts. The top is comparted in the friend, I was amazed to find, in the place of the dark, dingy though it did not approach the brightness of the cloth a same manner as the hull, and both top and bull are prided little creature I bad wrapped up, a beaulizard. It was only then that I discovered my specimen to be the so-called American chame leon. I was some what ashamed of my ignorance unti I met a certain naturalist from Michigan, who had made quite a collection of what he took to be what he took to be distinct species of saurians, and bat carefully preserve them in spirits, only to find upon inspection, that they wer all exactly alike in form and color all baving assumed a yellowish-brow a yellowish-brown

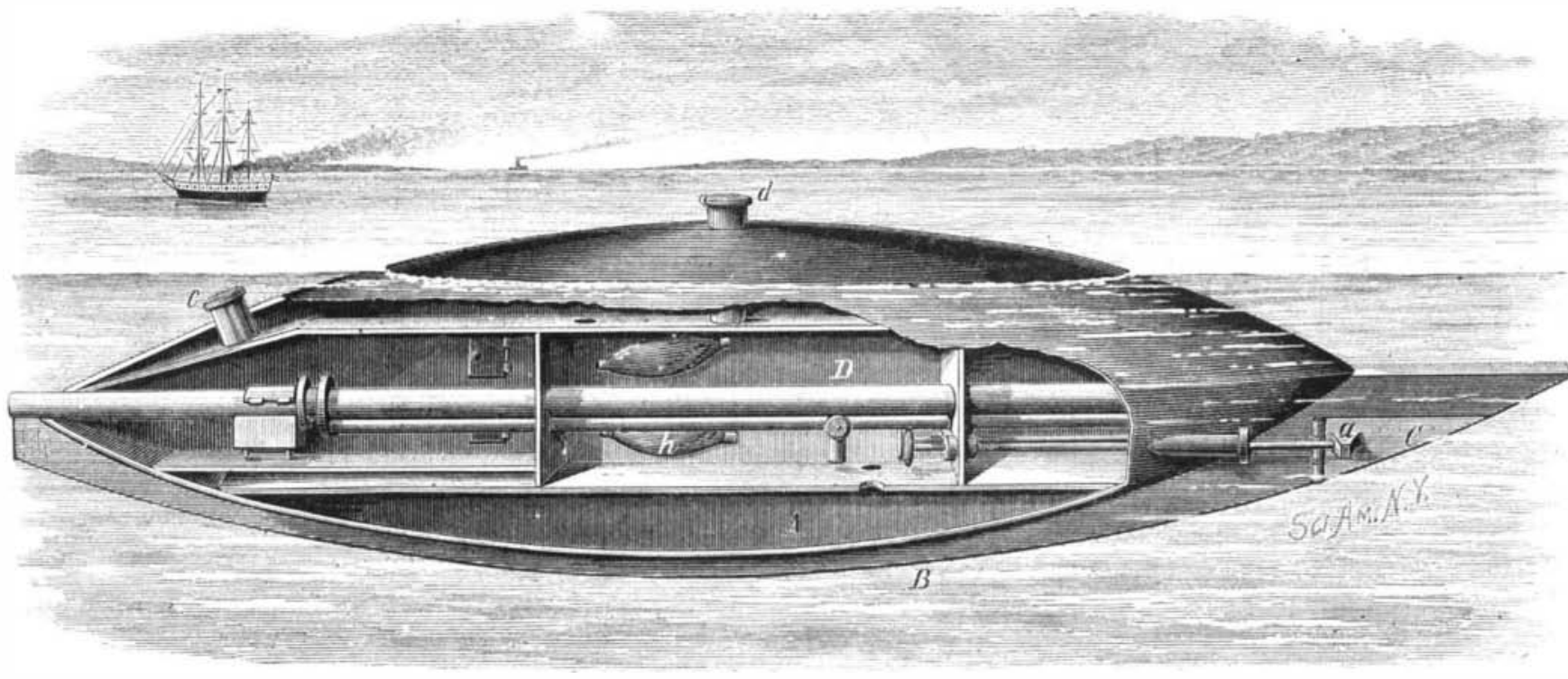

MORTENSEN'S TORPEDO BOAT.

near apex of the nose; the animal has no apparent external ears; it has bright, intelligent, almond-shaped eyes; large jaw, and four well defined teeth in the lower jaw, the intermediate space being filled with minute points; and four well developed legs, five toes upon each, each toe swelling out into a soft pad, terminating in a booked claw. The pad or middle of the toe, under the magnifying glass, shows an odd arrangement of folds or fiounces in the skin, each fiounce, one half of them pointing up and the other half down, as shown in the illustration. Thus may we explain the creature's ability to run up or down the side of a house with equal facility.

In the illustration I have shown the lizard upon my finger, with mouth open; the dark color representing its favorite green hue. At the bottom in the moss is the same animal in his gray coat. In the circle appears a magnified view of chowing the peculiar artangement of the folds of the skin upon the under side; and an enlarged view of the hind leg. and the head as it appeared under the glass while changing its color.

\title{
ATEW TORPEDO BOAT
}

The accompanying engraving represents partly in section a torpedo boat recently patented by Mr. H. Mortensen, of Leadville, Col. The hull $\mathbf{A}$, of the boat, has an arc-shaped keel, B, that runs the entire length, and projects beyond the stern. A portion of the keel is cut away at the stern to receive the rudder, $\mathrm{C}$, which is pivoted in the stpport thus that project is provided with two arms, $a$, one on each side, deliberately shook off his tail, and scampered away, leav- ceive the thrusts of the screw rods, which project through ing three fifths of his length wriggling upon the floor, where the stern of the boat, one on each side of the keel. The hul it continued to twist for some time. A drop or two of blood is divided into several compartments, one of which is demoistened the stump where the tail had been, but though signed to contain the men that operate the torpedo-project the loss of the latter appeared to cause no physical pain the ing mechanism, anolher contains the men who introduce the little cripple seemedashamed of his odd appearance and hid torpedo into the projecting apparatus and attach it to the himself in corners. He remained in my room for a month movable rod, and there are compartments for containing It either air or water, as occasion may require. In the upper nd interest all observers.

The negroes and even intelligent white inhabitants of the pressed air for the supply of the crew and for working the district frequented by this reptile tell many fabulous stories tioned, there is a compartment for containing water forced of its wonderful powers in this respect. Experiments with in against an air cushion. This chamber acts as an ac specimens which were in my possession at different times cumulator of power which is expended in working the torseemed to demonstrate that emerald green, gray, and sooty pedo projecting apparatus.

black and reddish yellow were the limits of its power. A cylinder containing a piston is placed longitudinally some time in or pleased it turned green; if agitated for in the hull, and provided with a loadi

return in blotches. Under an ordinary magnifying glass it The water required for working the piston may be forced could be seen that the hollow around the eye changed first. into the accumulator chamber before the boat is started. or comen the hexagonal plates upon the head showed the color, it may be force

late, the centers being the last points to turn. If a num- The rods by which the rudder is operated are threaded, ber of theee animals be placed in alcohol they will be found one being provided with a right hand and the other with a to he natural hue of the skin with the cor suitable motor or by

in alcohol. Two anoli that I kept in captivity proved very/casual observer would hardly have noticed the lizard mo. gentle pets, and would run over my hands waiting eagerly for tionless upon it.

me to catch fiies for them. Although quick in their Green is its favorite color, and black I never saw but in movements, and able by the help of their tail to spring quite one instance. When hiding in the Spanish moss or upon a a distance, these little animals never could capture the flies tree trunk it assimilates the gray, while yellowish red it asfor themselves unless I first crippled the insect by removing sumes with apparent effort. When put and left upon a red a wing. They loved the sunshine and fresh air; the latter substance or in a cigar box, the color of the latter it apthey would swallow occasionally in great gulps, expanding proaches very nearly. From tip of nose to tip.of tail meaa sort of pouch under their neck by the process. Though sures from five to six inches, the tail being three fifths of gentle when treated with kindness, when tormented they its total length. The head is rather large, triangular in would show fight, opening their mouths in a ludicrous way. shape, apex at the nose, and covered with small hexagonal

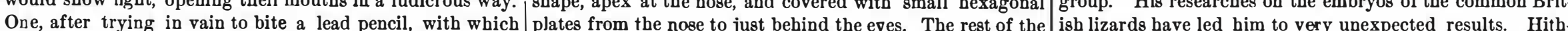
I had been stroking his back and otherwise plaguing him, $\mid$ body is covered with small papillous points; the nostrils are erto we bave been accustomed to regard the crocodiles and two entrances, d, provided wit hinged covers that are packed to render them wateright.

The compa: thents for containprovided with win dows, which open inwardly, so that theymay berepaired or replaced in case of breakage.

In each side of the boat there are recesses inclined in opposite directions each of these re screw propeller, the shaft of which ex tends into the boat, and is connected with'a motor. By means of these screws the boat may be propelled forward ackward, and raised or lowered, as may be required. The boat is capable of being operated wholly under the ater; or the top portion may be removed, when it may be propelled on the surface.

\section{Development of the Lizard.}

At a recent meeting of the Royal Society Prof. K. Parer presented a communication embodying part of bis work on the structure and development of the skull in the lizard oup. His researches on the embryos of the common Brit- 